\title{
Analysis of the Practice-theory Integration Teaching Pattern of Digital Electronic Technology based on Blended Concept
}

\author{
Liu Xueting ${ }^{1}$, Sun $\mathrm{Xia}^{2}$ \\ ${ }^{1}$ School of electrical and electronic engineering, Shandong University of Technology \\ Zibo, China \\ Email Address: liuxuet [AT] 163.com \\ ${ }^{2}$ School of electrical and electronic engineering, Shandong University of Technology \\ Zibo, China \\ Email Address: ltsunxia [AT] 163.com
}

\begin{abstract}
The course of digital electronic technology is an important technology basic course of electrical information specialty in universities. It has the characteristics of rapid development, practicality and systematicness. In this paper, the practice-theory integration teaching pattern of digital electronic technology under the Blended concept is put forward, and the teaching form of integration and development of innovation ability, practical ability and humanistic quality is explored in combination with actual situation. After two rounds of teaching practice, good results have been achieved.
\end{abstract}

Keywords-blended Learning; digital electronic technology; integration of theory and practice; teaching mode

\section{INTRODUCTION}

In recent years, with the rapid development of information technology in higher education, China's higher education is undergoing a series of new reforms. With the upsurge of the first round of research and practice, it is gradually realized that although online learning has the unique advantages of rich multimedia resources, convenient cooperative communication and friendly interaction, the learning effect is not as ideal as expected because of the lack of teachers' deep participation, so it cannot be completely replaced by traditional classroom teaching[1]. It has become a common concern for educators both at home and abroad to explore a teaching method that can not only play the role of teachers but also fully reflect the active participation of students online learning.

The blended learning (Teaching) mode came into being. Blended learning refers to a learning model that combines the advantages of traditional teaching with the advantages of online learning in the process of learning, and relies on modern information technology to achieve the purpose of effective learning. At present, the basic idea of blended learning is almost recognized, that is, in "appropriate" time, the "appropriate" learning technology is fit with the "appropriate" learning style, and the "appropriate" learners can be transferred "appropriate" ability to achieve optimal learning effects and learning methods ${ }^{[2]}$.

"Digital electronic technology" (Digital Electronic Technology) course is the basic technical course of electrical, automation, telecommunications and other electrical specialties. It is one of the key courses for the formation of students' professional quality. It has an important basic position in the setting of the curriculum system. In this paper, based on the pilot research project of school education information technology, has formed a teaching model of the integration of blended and physical integration in accordance with the rapid development of the digital electronic technology course, the close combination of theory and practice, the strong application characteristics and the rapid change of the learning methods of College Students by information technology ${ }^{[3]}$. After two rounds of teaching practice, good teaching results have been achieved.

\section{CURRENT SITUATION OF TEACHING OF DIGITAL ELECTRICITY IN COLLEGES AND UNIVERSITIES}

With the rapid development of digital electronic technology, more and more teachers at home and abroad have carried out various forms of teaching reform in combination with curriculum teaching, such as the introduction of the teaching methods and means such as case type, problem guide, project driven, information and so on ${ }^{[4]}$, as well as the practice of physical and practical teaching, which has made many achievements and promoted the construction and development of this course. However, there are still some problems in the teaching of digital electricity in Universities in 
China.

\subsection{Teaching content and teaching mode cannot be effectively integrated}

Most of the current teaching materials emphasize the comprehensiveness and systematicness of the theoretical basic knowledge, but ignore the practical training link and cannot meet the needs of the integration of physical and practical teaching. In traditional teaching, due to the constraints of the experimental hardware conditions, less experimental hours, or unreasonable time arrangement, cannot be done by the teacher at the same time to let the students operate, and the experimental courses are mostly confirmatory experiments, which leads to the students lack of intuitive understanding of the basic principles and concepts. This educational mode divorced from practice is not conducive to the cultivation of students' practical ability and innovative ability ${ }^{[5]}$.

\subsection{The contradiction between theory and practice teaching mode is much more than teaching content and teaching hours}

First of all, the " integration of theory and practice " requires the construction of knowledge and the cultivation of skills under the teaching mode of "speaking and doing, learning, thinking, watching and practicing" by combining the characteristics of the content of teaching content and the basis of the students' learning situation ${ }^{[6]}$. Therefore, in the process of teaching, teachers should carry out synchronous practice training besides theoretical teaching. This means that teachers should not only have profound theoretical foundation, but also have rich practical experience. Before class, students should consult relevant information and preview relevant knowledge. In the course, we should carry out operation exercises under the guidance of teachers, use software to design and simulate, design lap circuits, debug, and troubleshooting. Therefore, the theory and practice integration teaching mode needs more time than the traditional teaching mode.

Secondly, on the one hand, facing the gradual differentiation and complexity of digital electronic technology, new technologies and new devices are constantly emerging. In order to maximize the practice of students' practical ability and innovation ability, each chapter has set up practical training links, and the teaching content of digital courses is increased; on the other hand, the increase of the number of courses in the training program brings the compression of teaching hours ${ }^{[7]}$.

How to enable students to acquire a lot of knowledge efficiently in limited class hour is one of the challenges in the current teaching reform of digital courses.

\section{ANALYSIS OF THE PRACTICE-THEORY INTEGRATION TEACHING PATTERN OF DIGITAL ELECTRONIC TECHNOLOGY BASED ON BLENDED CONCEPT}

\subsection{Renewing the teaching content of the course}

The textbook is modified according to the rapid development of digital electronic technology, the close combination of theory and practice, the strong application of its own characteristics and the integrated teaching mode. In addition to the theoretical explanation, the basic framework of the integrated teaching process of "theory, simulation, design, experiment and test" has been added in most chapters. Based on teaching objectives, the application of basic theory, basic analytical methods and basic knowledge is highlighted in the teaching content. It avoids the complicated mathematical derivation and internal analysis process of integrated circuits, emphasizes analysis and application, and emphasizes the analysis of main parameters, external characteristics and logical functions. On the basis of retaining the traditional basic content, the application of integrated circuits is highlighted, the content of modern electronic technology is added, each knowledge point is divided into practical training tasks, and the integrated practical training links are set at the end of each chapter. The content of the adapted textbook and teaching content and the content of the experiment are unified. The relationship between the updated content and the traditional classical content, the relationship between the basic theory and the practical application, the relationship between the teaching knowledge and the training ability and the consciousness of innovation are better handled, and the training of the students' practical ability and innovation ability can be achieved to the maximum. It achieves the purpose of combining theory with practice, integrating teaching contents, and combining theory with practice.

\subsection{Creating an information learning environment}

With the rapid development of information technology in higher education, information technology has become an extension of the classroom teaching. The rich information learning environment can ensure the smooth implementation of the integrated teaching model of the digital curriculum. With the help of the comprehensive platform of school network teaching and the wireless network covered by the whole school, this course has built a resource rich network teaching integrated platform. According to the teaching needs of this course, the teaching activities column, the teaching resources column, the course construction column, the course management column and the course preview column are respectively constructed. There are two columns in teaching activities, including answering questions, course assignments, teaching notes, research teaching, online testing, podcasting unit and curriculum questionnaire. The 
teaching resources section has uploaded secondary topics such as course knowledge points, knowledge point preparation materials, teaching courseware divided according to knowledge points, electronic lesson plans, videos, etc., teaching courseware, experimental teaching, and class development. The various columns of the network teaching platform give full play to different teaching functions, teaching information release, independent learning and interactive communication, study results display, teaching effect feedback, learning track record, and teaching material accumulation. With the effective integration of information and curriculum construction, the traditional classroom teaching space is expanded into open space, the space time limit of classroom teaching is solved, and a new class of more broad, more powerful, more liberal and more individualized is developed for the teachers to achieve the teaching goal. The implementation of the teaching mode has constructed an ideal information learning environment. In the information learning environment, the traditional classroom and the online new classroom can give full play to their respective advantages. The classroom teaching mainly plays the role of teachers' guidance. The network classroom plays a variety of functions to guide students to learn and communicate independently, and the use of digital mobile phones and the Internet can also realize instant feedback in classroom teaching. At the same time, the advantage is that students do not have any obstacles in information technology. They soon understand that they have strong personality and can accept information quickly.

\subsection{Design and Practice of the practice-theory integration teaching pattern of digital electronic technology based on Blended concept}

The concept of blended education and the integrated teaching model of physical reality have the same theoretical basis, and follow the "constructivism" educational concept of "teachers as the dominant and the students as the main body". Based on the above situation, this paper designs the integrated teaching mode of digital electronic technology, theory and practice. This model gives full play to the advantages of the combination of the blended teaching mode and the line and line. It saves a lot of time for the students to practice the practical ability. It not only realizes the perfect combination of theory and practice, but also combines independent learning with cooperative learning, which can not only play the leading role of teachers, but also embody the students' self-study. A new way of learning.

According to the blended teaching mode, the teaching process of this course takes "three point two lines", that is, three time nodes in pre class, course and after class and two forms of teaching in line and line. Teachers and students do different teaching tasks respectively. Before class, the teacher designed the teaching plan, released the curriculum resources, and distributed the portable test box. The student set up a 4 person learning group, which is composed by a group leader. The assistance group helps teachers organize teaching and formative assessment. The specific teaching process is shown in Table 1. 
Table 1 Teaching process of digital electricity course

\begin{tabular}{|c|c|c|c|}
\hline node & form & Teacher & Students \\
\hline $\begin{array}{c}\text { pre- } \\
\text { course }\end{array}$ & offline & $\begin{array}{c}\text { Teachers prepare lessons and design teaching } \\
\text { plans. }\end{array}$ & Group study, PPT production. \\
\hline online & $\begin{array}{c}\text { The teacher released the preview list, previewed } \\
\text { the questions, and checked the homework of the last } \\
\text { class. }\end{array}$ & $\begin{array}{c}\text { Students preview the contents of the } \\
\text { next lesson according to the preview list, } \\
\text { read the micro lesson online, PPT, consult } \\
\text { the literature, have problems, discuss with } \\
\text { teachers, students and students, do } \\
\text { preview tests. }\end{array}$ \\
\hline $\begin{array}{c}\text { During- } \\
\text { class }\end{array}$ & offline \\
after- \\
hours
\end{tabular}

\subsection{Gradually improve the evaluation method}

In the course of curriculum development, according to the characteristics of digital electric course, we gradually improve the evaluation method that accords with the new teaching mode. Teaching evaluation adopts the combination of process and summative to evaluate students' learning situation, not only checking theory, but also focusing on ability. The final and usual grades are 50\%, usually including team performance and personal activities. The results of team activities include the performance of the team activities and the presentation of the results of the team activities. The results of the individual activities include the network test and the other (attendance, homework, class activity participation, hands-on practice, project, network platform use, questionnaire and related innovative practice results, etc.). In order to comprehensively evaluate the students' degree of knowledge and the application of knowledge, we will continue to build a more scientific, standardized and easy to operate evaluation scheme from several aspects, such as evaluation target, evaluation index, evaluation method, development evaluation, evaluation and evaluation.

\section{CONCLUSION}

In this paper, the research and exploration of the integration of theory and practice of digital electronic technology is just beginning. This teaching mode combines the characteristics of the digital curriculum itself, not only in the teaching 
practice, it combines the advantages of the traditional classroom teaching and the network teaching, but also provides the students with the opportunity to operate at the same time, to carry out the practical ability training, and to cultivate the students' independent thinking ability and innovation ability. A teaching mode based on integration of theory and practice is built. Since the establishment of the project in September 2015, it has experienced two rounds of teaching practice. The work has been carried out steadily in accordance with the reform plan under the joint efforts of the members of the project group, and good teaching results have been received. However, there are many difficulties in the course of the implementation of the course, such as the implementation of the network teaching needs teachers, students to invest more time, the number of students, the classroom discussion is not well controlled, the design topic should be diversified to the students at different levels. To explore the teaching methods of blended teaching mode in large class, and to continue to increase the proportion of process assessment, and to form a more reasonable and standardized way of evaluation. These are all to be explored and perfected continuously in the course of our teaching and research in the future.

\section{REFERENCES}

[1] Yu Shengquan, Lu choly, Chen Shengjian. Blended teaching in the network environment-- A new teaching model[J]. Chinese University Teaching, 2005(10):50-56.(In Chinese)

[2] Han Xibin, Wang Yuping, Zhang Tiedao, et al. Welcome to the Digital University: long distance, blended and online learning-- translation, interpretation and research[M]. Tsinghua University press, 2016.

[3] Kang Huaguang. Fundamentals of electronic technology, digital part. Fifth Edition[M]. Higher education press, 2006.

[4] Yang Chunling, Zhu Min, Zhang Yan. Exploration and practice of research-based teaching method of digital electronic technology foundation[J]. teaching in Chinese universities, 2014 (2): 58-60.

[5] Deng Naijia. Practice and thinking of the teaching mode of "integration of theory and practice"--Applied to the teaching of digital electronic technology in University[J]. 2014 (13): 27-27.

[6] He Kehang. The theory and method of deep integration of information technology and curriculum[J], teaching in Chinese universities, 2005 (3): 16-19.

[7] Sun Lijun, Zhang Xiaodong, Luke. "Digital electronic technology" course teaching reform [J]. China power education, 2013 (13): 67-68. 